\title{
The cost of electromechanical equipment in a small hydro power storage plant
}

\author{
Gaydaa AlZohbi \\ Prince Mohammad Bin Fahd University, Al-Khobar, KSA, galzohbi@ pmu.edu.sa \\ ORCID: 0000-0002-0697-993X
}

Arrived: 04.09.2018 Accepted: 10.11.2018 Published: 31.12.2018

\begin{abstract}
Pumped hydroelectric storage (PHS) is the most established technology for utility-scale electricity storage. To take investment decision for the development of small hydropower projects, technical feasibility and financial viability are considered to be the foremost requirements. The cost of electro-mechanical equipment means a high percentage of a small hydro-power plant budget (around $30 \%$ and $40 \%$ of the total sum). It seems from this importance of the determination of that cost, which could directly influence the project feasibility. An overview of existing methods to estimate the cost of hydro turbines is presented in this paper. Empirical formulas to estimate the cost of centrifugal pump for a power $\leq 2 \mathrm{MW}$ and PAT (pump as turbine) for a power $\leq 550 \mathrm{~kW}$. In addition, new correlations have been developed to estimate the cost of hydraulic turbines (Pelton, Kaplan, Francis and Francis reversible) for a power $>2$ MW were developed through statistical analysis of cost data obtained from pumps and hydraulic turbines manufactures. The cost of EM equipment increases for high power levels but it decreases for high head.
\end{abstract}

Keywords: Pump as turbine, Conventional turbines, Small hydropower

Cite this paper as:

AlZohbi, G. The cost of electromechanical equipment in a small hydropower storage plant. Journal of Energy Systems, 2018; 2(4): 238-259, DOI: 10.30521/jes.457288

(C) 2018 Published by peer-reviewed open access scientific journal, JES at DergiPark (www.dergipark.gov.tr/jes) 


\section{INTRODUCTION}

Pumped Hydro Storage (PHS) is a mature and cost effective bulk technology for storing renewable energies. Pumped-hydro storage schemes currently provide the most commercially important means of large-scale grid energy storage and improve the daily capacity factor of the generation system. The development of new adjustable-speed technology allows pumped storage to provide more frequency regulation services in generation and pump modes and fast ramping, both up and down. This is important since the high penetration of intermittent renewable energy (e.g., wind and solar) requires more system flexibility. A typical conventional PHS consists of two interconnected reservoirs, tunnels that converts water from one reservoir to another (water conductors), a power house with a pump/turbine and a motor/generator, and a transmission connection (Fig. 1). PHS employs off-peak electricity to pump the water from a lower reservoir to an upper one (charging), and then converts it back during the peak periods ("discharging") to generate electricity. To be feasible, these plants require very specific site conditions with a proper ground conformation, large elevation difference between the reservoirs to provide sufficient capacity and water availability. According to Hino and Lejeune [1], PHS serves the grid in wide range such as (1) flexible start/stop and fast response speed, (2) ability to track load changes and adapt to drastic load changes, and (3) can modulate the frequency and maintain voltage stability. PHS can be classified according to their machine setup. Three main technical setups exist:

Turbine and pump as separate units: which can be connected to the generator/motor alternately; this system has a higher efficiency because units can be optimized separately but it is more complex.

Turbine and pump as single reversible unit (reversible pump-turbine): which is directly connected to the generator/motor; it reduces the construction cost (up to $30 \%$ ) but has around $2 \%$ lower efficiency [2].

Pump as turbine (PAT): centrifugal pump and diagonal could be used as PAT that can operate in pumping monde and in turbine mode pump.

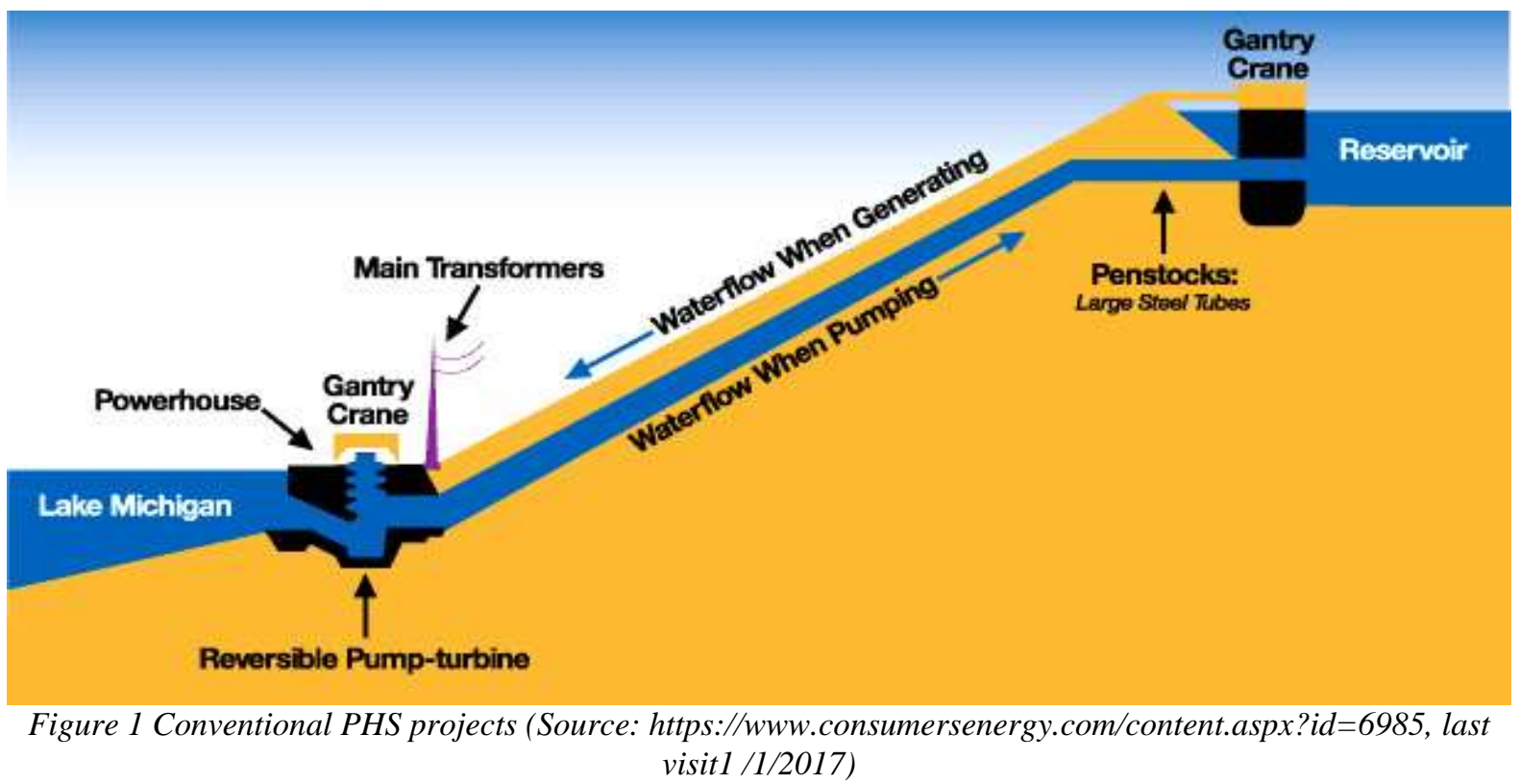

The electro-mechanical equipment used in hydropower plants is a mature technology, and the cost is strongly correlated with the capacity and the net head of the hydropower plant. The design decision of PHES is a compromise between minimizing capital costs, maximizing efficiency and the number of generating units to ensure the best availability. The installation cost of the small hydropower plant is 
mainly divided into two parts- civil works and electromechanical equipment. The cost of electromechanical equipment (turbine-alternator and regulator) represents the most important element of a small hydro-power plant. The cost of electro-mechanical components in large hydro is around $20 \%$ but in micro hydro it is relatively high and varies from $35-40 \%$ of the total project cost [3]. It seems from this importance of the determination of that cost, which could directly influence the project feasibility [4].

In the present paper, new correlations have been developed to determine the cost of pump for a power range $\leq 2 \mathrm{MW}$, PAT for a power range $\leq 550 \mathrm{~kW}$ and of hydraulic turbines (Pelton, Kaplan, Francis and Francis reversible) for a power range above $2 \mathrm{MW}$. The originality of this paper is the development of new correlations to estimate the cost of hydraulic turbines for a high power range, the power range for the correlations found in the literature are for $5 \mathrm{MW}$ maximum. In addition, an overview of existing correlations to estimate the cost of conventional turbines has been presented.

\subsection{Types of Electromechanical Equipment}

An electromechanical equipment is more considered to be the equipment and system required to develop the energy available in impound or flowing water to convert it into electrical energy, to control it and to transmit it to the power grid. The major electromechanical component of power plants is the turbine, generator, control and protection equipment and transformer. The major items in terms of cost are the turbine and the generator, it could be conventional turbines or pumps as turbines.

\subsubsection{Conventional Turbines}

The turbine is the main piece of equipment in the hydro power scheme that converts energy of the falling water into a rotating shaft power. Turbines can be either impulse or reaction turbines. The basic turbine classification is given in Fig. 2.

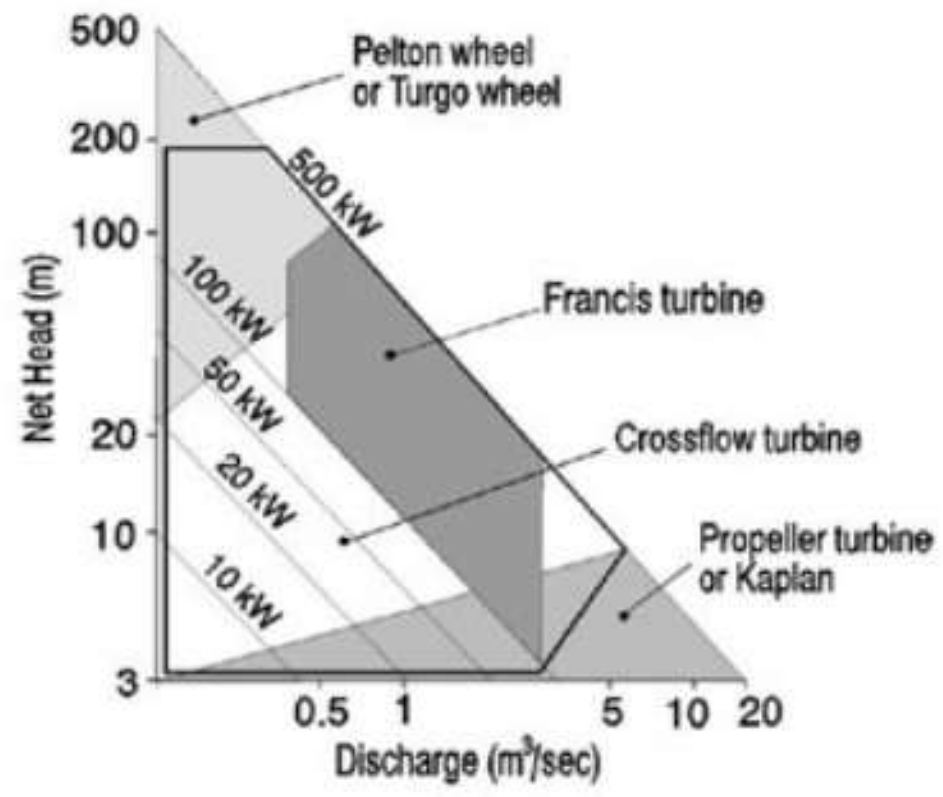

Figure 2 Head-flow ranges of small hydro turbines [5]

The rotating part (called 'runner') of a reaction turbine is completely submerged in water and is enclosed in a pressure casing. The runner blades are designed in a manner such that the pressure difference across their surface imposes lift which cause the runner to turn/rotate. 
The impulse turbine (as the name suggests) on the other hand is never immersed in water but operates in air, driven by a jet (or jets) of water striking its blades. The nozzle of the penstock converts the head of the water (from forebay tank) into a high-speed jet, it hits the turbine runner blades, deflect the jet so as to utilize the change of momentum of the water and converting this as the force on the blades enabling it to rotate.

Impulse turbines are usually cheaper than reaction turbines because there is no need for a pressure casing nor for carefully engineered clearances [5]. They are also only suitable for relatively higher heads.

The selection of the right type of turbine for given site conditions is one of the most important factors influencing efficiency and cost. It depends mainly on two of the site characteristics - head and flow available. Different turbines are used for each situation, with high head systems normally using turbines such as Pelton wheels or Turgo runners, according to Western North Carolina Renewable Energy Initiative (2007). Low head systems typically use Francis, Kaplan or Cross flow turbines to turn the generator. A rough guide to turbine choice is given in Fig. 3.

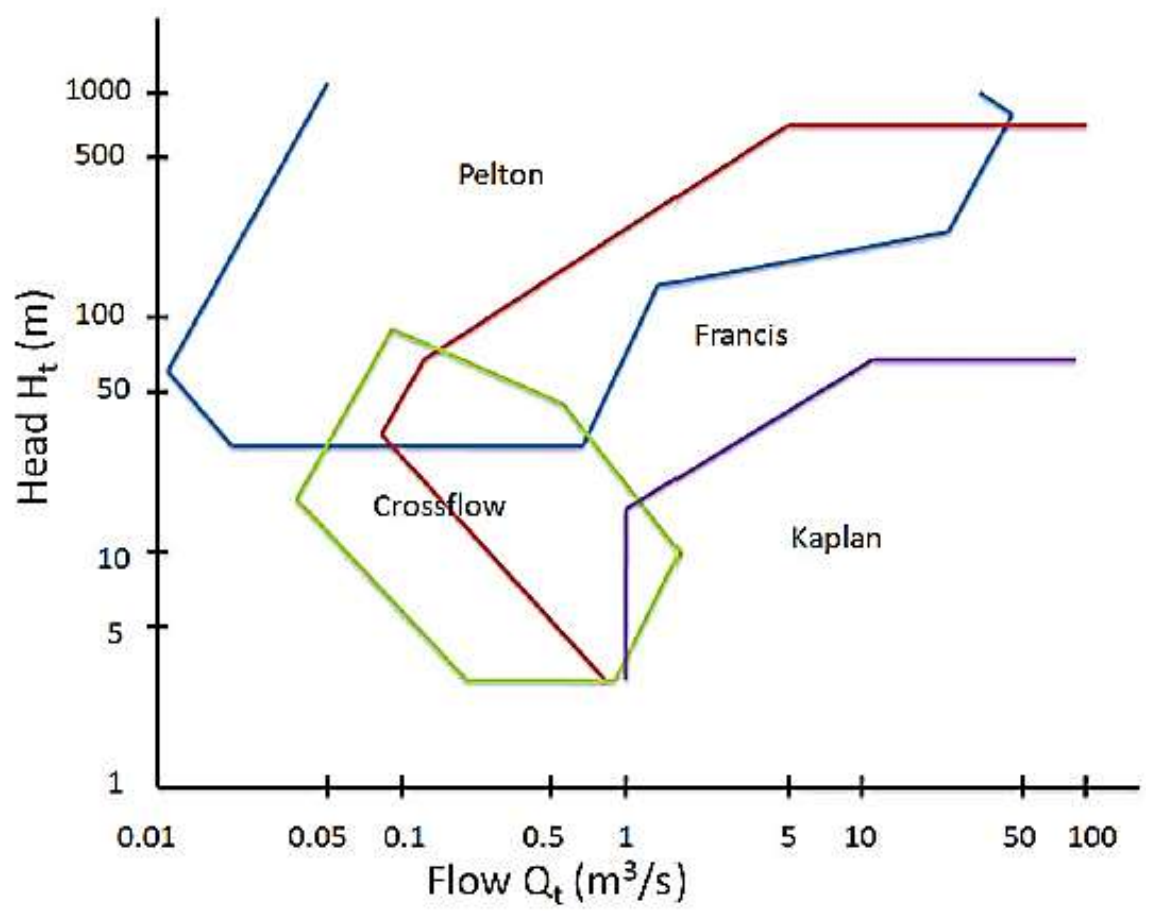

Figure 3 Guide to turbine type operating ranges [7]

All turbines have a power-speed characteristic. This means they will operate most efficiently at a particular speed, head and flow combination. Thus, the desired running speed of the generator or the devices being connected / loading on to the turbine also influence selection. Other important consideration is whether the turbine is expected to generate power at part-flow conditions. The design speed of a turbine is largely determined by the head under which it operates.

A significant factor in the comparison of different turbine types is their relative efficiencies both at their design point and at reduced flows. Typical efficiency curves are shown in the Fig. 4. An important point to note is that the Pelton and Crossflow turbines retain very high efficiencies when running below design flow; in contrast the efficiency of the Propeller and Francis turbines falls away more sharply if run at below half their normal flow. Most fixed-pitch propeller turbines perform poorly except above $80 \%$ of full flow. 


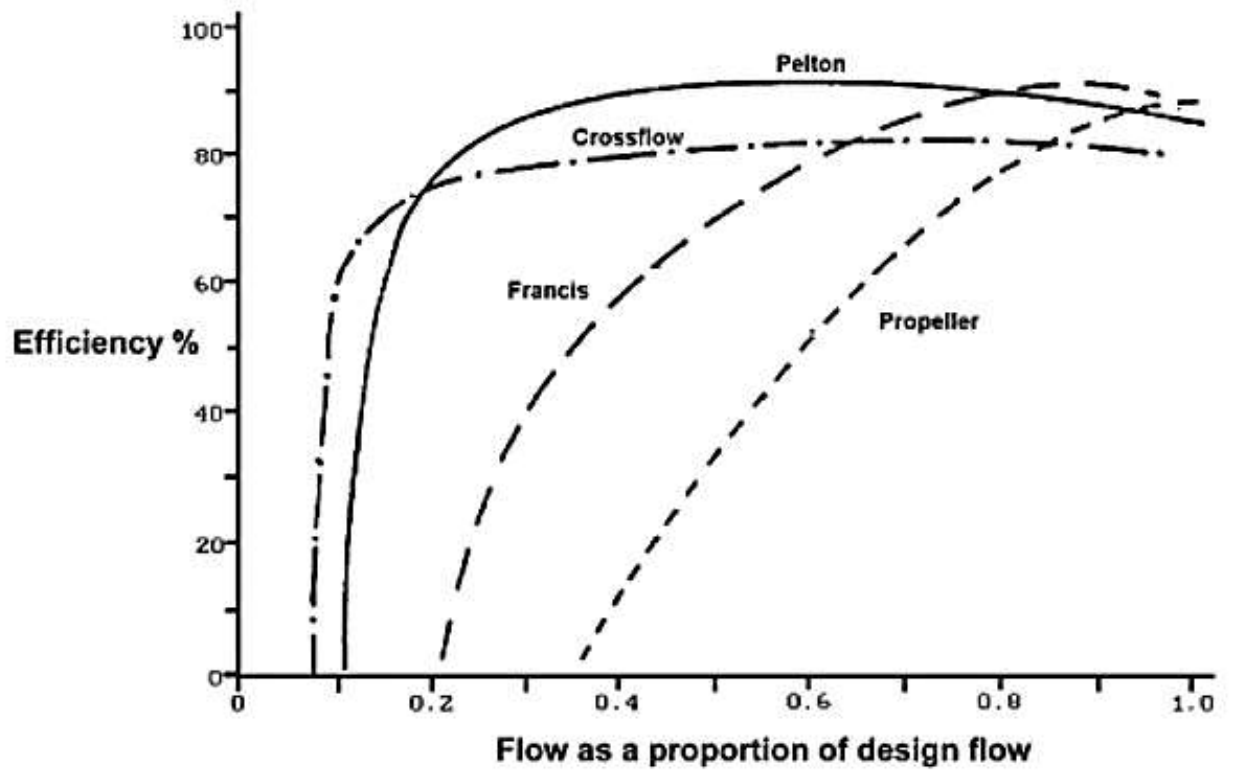

Figure 4 Efficiency of turbines [6]

\subsubsection{Pump as Turbine (PAT)}

Centrifugal pumps are physically and hydraulically similar to Francis turbines (without flow control device). Centrifugal pump converts the mechanical energy of impeller into pressure energy and kinetic energy whereas Francis turbine converts the pressure energy and kinetic energy of water into mechanical energy of impeller. Therefore, if a centrifugal pump is operated in reverse mode, it can function as a Francis turbine. In 1930, Thomas and Kittredge accidentally realized that pumps could operate very efficiently in the turbine mode when they were trying to assess the complete characteristics of pumps [6]. Knapp published in 1941 the complete pump characteristics for few pump designs based on experimental investigations [7]. The concept of pumped storage power plants, in the range of 50-100 MW, was evolved mainly in developed countries to satisfy the peak power demands in 1950s and 1960s. In later years, chemical industries became another area for the application of PATs for energy recovery. The technology for the use of PAT for electrical power generation was not available earlier. However advances in electrical machinery control technologies made possible the utilization of pump rotating in reverse mode for power generation [8]. Agostineli and Shafer [9] tested many pumps in turbine mode over the years and concluded that when a pump operates in a turbine mode, its peak efficiency is same as in pump mode; its mechanical operation is smooth and quiet; head and flow at the best efficiency point are higher than that in pump mode and the power output is higher than that the pump input power at its best efficiency. Baumgarten \& Guder (2005) propose that the major benefit is that mass production of pumps means that they are comparatively much more cost-effective than conventional turbines. Derakhshan \& Nourbakhsh (2008) state that pumps are relatively simple and easy to maintain and have a competitive maximum efficiency when compared to conventional turbines. Ramos and Boraga [10] carried out the analysis under steady and unsteady conditions based on Suter parameters [11] in order to identify the behavior similitude between turbines and pumps, when the pump is operated in turbine mode. The aim of the study was to get more economical solution to recover some part of the dissipated energy, it was concluded that the use of PATs allows obtaining a maximum relative efficiency up to 80 $\%$, depending on the type of the runner. Isbasoiu et al. [12] discussed various methods for controlling the PAT vis. By using the fixed load system, by manual governing of turbine/electric load and by automatic control of ballast load. Fercatto et al. [13] studied the performance of multistage pump in a water supply system numerically and experimentally and found that the response of PAT may differ from that of PRV (pressure reducing valve). Yang et al. [14] numerically investigated three PATs covering low, medium and high specific speed with different blade wrap angles to study the influence of blade wrap angle on PAT. The results showed that there is an optimal blade wrap angle for a PAT to achieve the highest efficiency and it decreases with an increase in specific speed. Also, the PATs flow 
versus head $(\mathrm{Q}-\mathrm{H})$ and flow versus shaft power $(\mathrm{Q}-\mathrm{P})$ curves were decreased and the flow rate at the $\mathrm{BEP}$ was increased with the decrease of the blade wrap angle.

The advantages of the use of PATs are in view of their lower initial and maintenance cost. The initial cost of the machine affects the cost of the hydropower plants only in initial phase of the project; however, the lower efficiency of the machine affects the plants on daily basis. Hence, to justify the use of PAT in hydropower plants, few investigators have applied different approaches vis. Comparison of various project investments opportunities based on several financial parameters, evaluations of various renewable energy options, cost analysis of hydropower plant by considering conventional hydro turbine as well as an equivalent PAT as prime movers. Alatorre-Frenk [15] carried out the cost analysis of micro hydropower plant based on PAT and conventional hydro turbine and it was found that, in spite of the lack of flow control devices in PATs, usually the large reduction in cost makes them more economical than conventional turbines, it was recommended to use an external device to damp the pressure fluctuations instead of using a very thick-walled penstock which led to additional cost savings. Motwani [16] carried out an ALCC analysis for $3 \mathrm{~kW}$ capacity micro-hydro power plant, by considering PAT and an equivalent Francis turbine as prime mover, based on initial cost of the project, capital recovery factor and annual expense. Based on this analysis, the ALCC and the cost of electricity generated per $\mathrm{kWh}$ were found to be $85 \%$ and $80 \%$ less for PAT compared to Francis turbine, which has justified the use of PAT in place of Francis turbine for their case study. Chuenchooklin [17] presented the cost analysis for pico-hydropower for a farming village in Thailand where pump was installed as turbine. The results show the produced electricity was enough for the indoor electrical appliances such as electric light and some house-ware appliances. It was recommenced to install PAT based pico/micro/mini-hydro power plants in larger farming villages where the higher head and larger flow rate may be available depending on the topography characteristics.

Since there are many different types of pumps that can be used as a turbine as in Ref. [18] (shown in Fig. 5) to aid the choice of an adequate pump for any project based on total head and flow rate. Luneburg and Nelson reported that all centrifugal pumps from low to high specific speed, radially or axially split, single or multistage, horizontal or vertical installations can be used in reverse mode [19]. It can be noticed from Figure 5 that multistage pumps are only used in cases where the head is very high, and when the flow rate is high either multi-flow pumps or a system of single flow pumps in parallel is used.

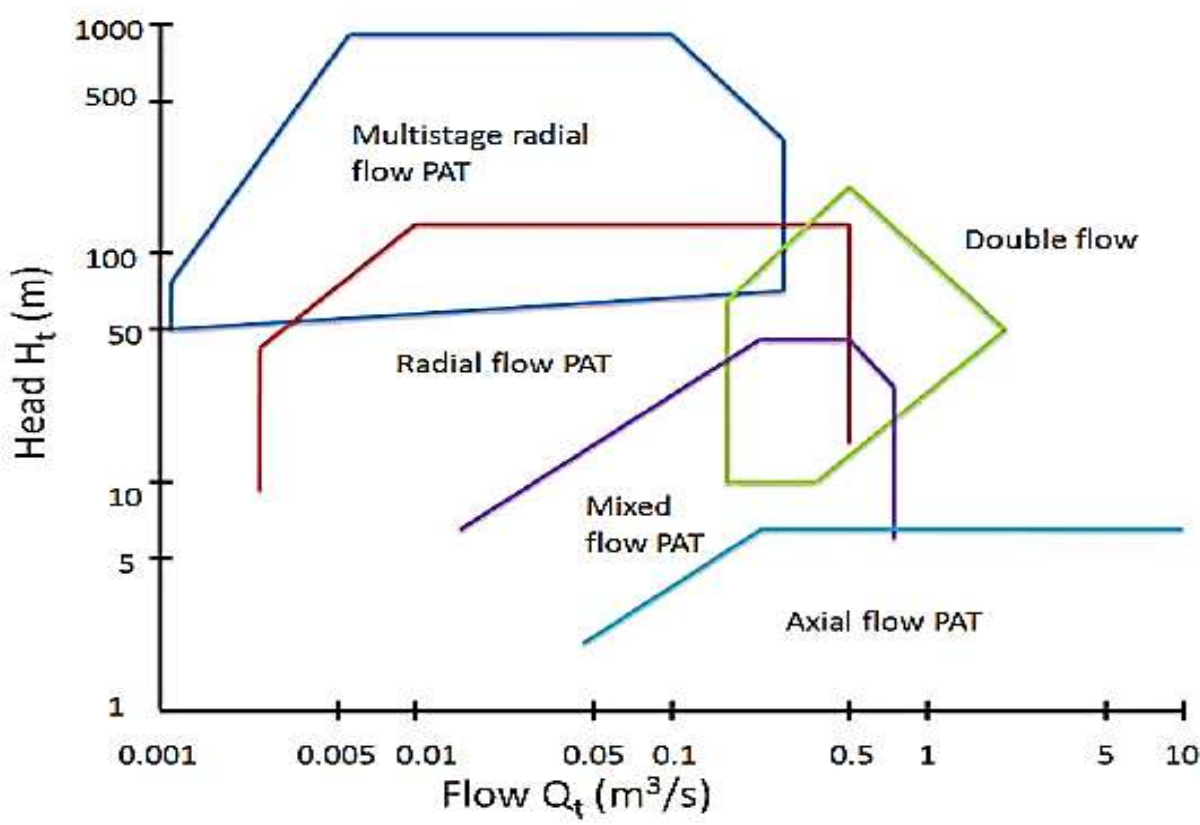

Figure 5 Choice of pumps for PAT applications [21] 


\section{OVERVIEW OF EXISTING ESTIMATING TECHNIQUES TO ESTIMATE THE COST OF EM EQUIPMENT}

Several mathematical correlations were proposed in the literature over the past years for the estimation of the electro-mechanical equipment costs $(\mathrm{C})$, most of them being dependent on power $(\mathrm{P})$ and net head $(\mathrm{H})$ according to the following equation model:

$$
C_{E M}=a P^{b} H^{c}
$$

where $a, b$ and $c$ are coefficients statistically determined on the basis of the available database of small hydro power plants

In 1979, J.L. Gordon, the pioneer who made remarkable contributions to cost estimating techniques for hydro projects, developed a correlation of electromechanical cost for projects below $5 \mathrm{MW}$ at existing dams [20].

$$
C_{E M}=9000 P_{k W}^{0.7} H_{m}^{-0.35} \quad \text { for } \mathrm{P}<5 \mathrm{MW}(\mathrm{US} \$, 1979)
$$

where $C_{E M}$ is the cost of electromechanical equipment, $P$ is installed capacity in $\mathrm{kW}, H$ is hydraulic head in meters.

In 1979, based on the data of plants located in Sweden, Lasu and Persson [21] developed a similar equation.

$$
C_{E M}=97436 P_{k W}^{0.53} H_{m}^{-0.53}
$$

In 1984, Gulliver and Dotanm developed a new correlation to estimate the cost of electromechanical equipment [22].

$$
C_{E M}=9600 P_{k W}^{0.82} H_{m}^{-0.35} \quad(\mathrm{US} \$, 1984)
$$

In 1998, Whittington et all [23], proposed a new correlation to estimate the specific cost of electromechanically equipment:

$$
C_{E M}=31500 P_{k W}^{0.25} H_{m}^{-0.75} \quad(\mathrm{US} \$ / \mathrm{kW}, 1998)
$$

In 2000, Voros et all developed a new correlation based on Plants located in Greece [24].

$$
C_{E M}=40000 P_{k W}^{0.70} H_{m}^{-0.35} \quad(\mathrm{US} \$, 2000)
$$

In 2000, Chenal developed a new correlation based on Plants located in Switzerland [25], to estimate the specific cost of eletromechanical equipment.

$$
C_{E M}=1000\left(34.12+16.99 P_{k W}^{0.91} H_{m}^{-0.14} \quad(€ / \mathrm{kW}, 2000)\right.
$$

In 2001, based on Austrian data, Matthias, Doujak and Angerer [26] have developed an estimation of investment costs for projects with $\mathrm{P}<2 \mathrm{MW}$ and $\mathrm{H}<15 \mathrm{~m}$. The overall costs of the hydro plant development or renovation were represented as a function of hydraulic head and capacity of a hydro site: 


$$
C_{I}=K P^{m} H^{-0.3} \quad \text { for } \mathrm{P}<2 \mathrm{MW} \text { and } \mathrm{H}<15 \mathrm{~m}(\mathrm{ATS}, 2001)
$$

Where $C_{I}$ is the investment cost in Austrian Shillings (ATS), $m$ is a constant, $K$ is a constant (ATS), $P$ is plant capacity $(\mathrm{kW})$ and $H$ is designed head. The costs of different components of the investment costs are given by the same formulae but with different values for constant $K$ and $\mathrm{m}$. The cost included direct and indirect investment costs. The interest rates on investment, O\&M costs, and influence of ecological and environmental measures on energy costs were also studied.

In 2001, Papantonis published 'Small hydroelectricity plants' [27] where he estimated the costs of different components of the hydro plants based on the European data available at that time. This included the formulae to estimate the costs of electromechanical equipment (turbine, speed control and generator), cost of different types of turbines (Kaplan, Francis and Pelton), cost of generators, speed controls, dams and intakes as function of hydraulic characteristics of a hydro site such as head and flow or head and capacity. The cost of electromechanical equipment confirmed Gordon's equation with an inflation rate adjustment:

$$
C_{E M}=20570 P_{k W}^{0,7} H_{m}^{-0,35} \quad(€, 2000)
$$

The estimates cost for different turbines types are shown below:

$$
C=a^{*} Q^{n} * H^{m} \quad \text { Or } C=b * k W^{n} * H^{r} \quad(€, 2000)
$$

The values of constants $a, b, n, m$ and $r$ can be found in the Table 1 . These values should be used with care as they are based on European data much of which is out of date.

Table 1 Values of constants $a, b, r, m$ and $n$ for different types of turbines [11]

\begin{tabular}{lrcccc}
\hline Turbine type & \multicolumn{1}{c}{$\mathrm{A}$} & $\mathrm{n}$ & $\mathrm{m}$ & $\mathrm{b}$ & $\mathrm{r}$ \\
\hline Kaplan & 87.336 & 0.410 & 0.2000 & 35.446 & -0.2100 \\
Francis & 96.998 & 0.481 & 0.1953 & 33.676 & -0.2858 \\
Pelton & 115.420 & 0.444 & 0.2582 & 43.465 & -0.1858 \\
\hline
\end{tabular}

In 2005, Kaldelis \& all developed an empirical equation to evaluate the cost of electromechanical equipment for small hydro power plant [28]. The equation is:

$$
C_{E M}=3300 P_{k W}^{-0.7} H_{m}^{-0.107} \quad(€ / \mathrm{kW}, 2005)
$$

In 2008, Based on the received data from companies such as Alstom, Andritz, Gilbert Gilkes \& Gordon Ltd, NHT and Voith Siemens, a formula was developed to estimate the cost of electromechanical equipment for small scale hydro plants [29]:

$$
C_{E M}=1200 P_{k W}^{0.56} H_{m}^{-0.112} \quad(£, 2008)
$$

In 2009, Ogayar and Vidal developed empirical equation to estimate the cost of electromechanical equipment based on Spanish data for a project below 2 MW (Ogayar and Vidal 2009a) [4]:

$$
C_{E M}=K_{1} P^{K_{2}} H^{K_{3}} \quad \text { for } \mathrm{P}<2 \mathrm{MW}(€ / \mathrm{kW})
$$

in which $P$ (in $\mathrm{kW}$ ) and $H$ (in meter) are the same as defined earlier and cost is given in $€ / \mathrm{kW}$, to obtain the total cost, the cost per kilowatt is multiplied by the capacity $\mathrm{P}$. The cost parameters are shown in Table 2 . 
Table 2 Cost parameters for hydro turbines and $R 2$ [5]

\begin{tabular}{lcrrr}
\hline Turbine & $\mathrm{K}_{1}$ & \multicolumn{1}{c}{$\mathrm{K}_{2}$} & $\mathrm{~K}_{3}$ & $\mathrm{R}^{2}(\%)$ \\
\hline Pelton & 17693 & -0.3644725 & -0.281735 & 93.16 \\
Francis & 25698 & -0.560135 & -0.127243 & 72.26 \\
Kaplan & 33236 & -0.58338 & -0.113901 & 91.70 \\
\hline
\end{tabular}

A series of research efforts by Singal \& al. (2008a, 2008b, 2010) [30-32], based on project data in India, developed correlations of component costs to $\mathrm{P}(\mathrm{kW})$ and $\mathrm{H}(\mathrm{m})$ for canal-based, low -head dam-toe, and low- head run-of -river SHP schemes, respectively.

$$
C_{E M}=63346 P_{k W}^{-0.1913} H_{m}^{-0.2171} \quad(\mathrm{Rs} / \mathrm{kW}), 2010
$$

In 2010, Aggidis \& al. (2010) [29] pointed out that cautions needed when using Papantonis (2001) equations as they are based on inconsistent European data, much of which is out of date. Meanwhile, based on project data for hydro sites in the northwestern region of the UK, Aggidis \& al. (2010) developed cost estimate equations for overall plant and electromechanical equipment (Table 3).

Table 3 Summary cost equations for electromechanical equipment [13]

\begin{tabular}{|c|c|c|}
\hline Kaplan & Francis & Pelton \\
\hline $\begin{array}{l}0.5 \leq \mathrm{Q}<5 \mathrm{~m}^{3} / \mathrm{s}: \\
C(\mathfrak{E})=3500\left(P^{0.68}\right)\end{array}$ & $\begin{array}{l}0.5 \leq \mathrm{Q}<2.5 \mathrm{~m}^{3} / \mathrm{s}: \\
C(\mathfrak{f})=122,000\left(P / H^{0.5}\right)^{0.07}\end{array}$ & \multirow{3}{*}{$C(\mathfrak{E})=2600\left(P^{0.54}\right)(\mathfrak{E})$} \\
\hline \multirow{2}{*}{$\begin{array}{l}5 \leq \mathrm{Q} \leq 30 \mathrm{~m}^{3} / \mathrm{s}: \\
C(£)=14000\left(P^{0.35}\right) \quad(£)\end{array}$} & $\begin{array}{l}2.5 \leq \mathrm{Q}<10 \mathrm{~m}^{3} / \mathrm{s} \\
C(£)=223,000\left(P / H^{0.5}\right)^{0.11}\end{array}$ & \\
\hline & 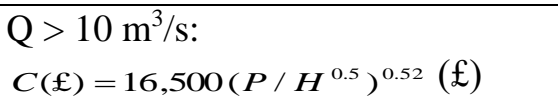 & \\
\hline
\end{tabular}

Recently, Giovanna \&al [33] proposed a new methodology to estimate the cost of electro-mechanical equipment, this methodology decomposes the cost of electro-mechanical equipment into three terms:

$$
C_{E M}=a H_{m}^{b}+c Q_{l / s}^{d}+e P_{k W}^{f}+\mathrm{g} \quad(€, 2016)
$$

where $\mathrm{a}, \mathrm{b}, \mathrm{c}, \mathrm{d}, \mathrm{e}, \mathrm{f}$ and $\mathrm{g}$ are correlation constants and dependents on the type of turbine. The developed correlations to estimate the cost of Pelton, Kaplan and Francis turbines are presented in Table 4.

Table 4 Summary cost equations for electromechanical equipment developed by Giovanna [14]

\begin{tabular}{ll}
\hline Turbine & \\
\hline Pelton & $C_{E M}=1358677.67 H_{m}^{0.014}+8489.85 Q_{l / s}^{0.515}+3382.1 P_{k W}^{0.416}-1479160.63$ \\
Francis & $C_{E M}=190.37 H_{m}^{1.27963}+1441610.56 Q_{l / s}^{0.03064}+9.62402 P_{k W}^{1.28487}-162157.28$ \\
Kaplan & $C_{E M}=139318.161 H_{m}^{0.02156}+0.06372 Q_{l / s}^{1.45636}+155227.37 P_{k W}^{0.11053}-302038.27$ \\
\hline
\end{tabular}

The electromechanical components include (1) turbine with governing system; (2) generator with excitation system, switch gear, control and protection equipment; (3) mechanical and electrical auxiliaries; and (4) main transformer and switchyard equipment. The most of cost correlations to estimate the cost of EM equipment in PHS that have been developed in the literature are represented in Tables 5 and 6. 
Table 5 Cost correlations found in the literature

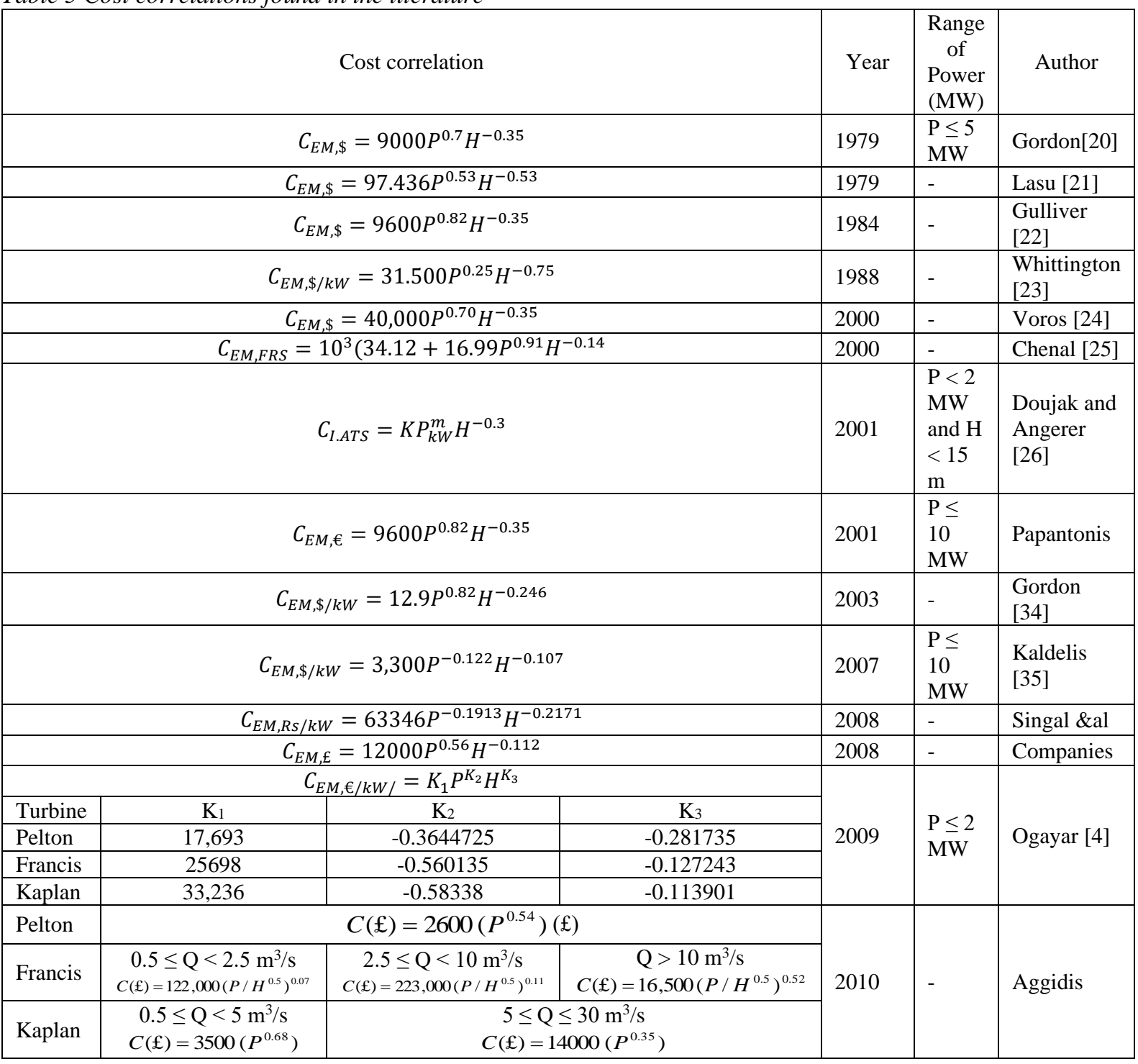

\section{DEVELOPMENT OF COST CORRELATIONS TO ESTIMATE THE COST OF ELECTROMECHANICAL EQUIPMENT}

The mathematical model used in the literature to estimate the cost of EM equipment in terms of identified parameters is selected which is defined as $[4,20]$ :

$$
C_{E M, P A T}=a P^{(b)} H^{c}
$$

Where $a, b$ and $c$ are coefficients; $C$ is the cost; $P$ is the installed capacity, $\mathrm{H}$ is the head.

A best-fit analysis should be carried out for diverse cost to estimate these coefficients. 


\subsection{Cost Correlations Methodology}

The methodology has been used to estimate these coefficients is presented here:

The expression of initial cost of electro-mechanical equipment is:

$$
C=a P^{b} H^{c}
$$

By applying logarithms, the following expression is obtained

$$
\log (C)=\log \left(a P^{b} H^{c}\right)=\log (a)+b \log (P)+c \log (H)
$$

By carrying out a variable change, the flowing expressions as obtained:

$$
\begin{aligned}
& Z=\log (C) \\
& X=\log (P) \\
& Y=\log (H)
\end{aligned}
$$

Therefore, the following expression is obtained:

$$
Z=\log (a)+b X+c Y
$$

Substituting data of cost, power and head of every plant whose data are known in the previous expression, it is obtained:

$$
\begin{aligned}
& Z_{1}=\log (a)+b X_{1}+c Y_{1} \\
& Z_{2}=\log (a)+b X_{2}+c Y_{2} \\
& Z_{n}=\log (a)+b X_{n}+c Y_{n}
\end{aligned}
$$

Then we proceeded to search the plane $A X+B Y+C Z+D=0$ with the best fit to data $(X u, Y a k, S k i)$ and carrying out a multiple regression between the independent variables $(X, Y)$ and $(Z)$

$$
A X+B Y+C Z+D=0
$$

Constants $a, b$ and $c$ are obtained by comparing Equations (19) and (22) through the following expressions:

$$
\begin{aligned}
& a=e^{-\frac{D}{C}} \\
& b=-\frac{A}{C}
\end{aligned}
$$




$$
c=-\frac{B}{C}
$$

Therefore, the function of cost can be expressed as:

$$
C=a P^{b} H^{c}
$$

The constants $\mathrm{a}, \mathrm{b}$ and $\mathrm{c}$ are determined by using enough data of costs depending on net head and power.

Costs are dependent on the variables, head and power but as well as by the typology of turbines. In this paper, the discriminant between different types of turbines is carried out to evaluate the constants $a, b$ and $\mathrm{c}$.

The developed cost correlations of hydraulic turbines (Pelton, Kaplan, Francis and Francis reversible), pumps and pump as turbines (PAT) are presented here below.

\subsection{Hydraulic turbines}

The most of the existing correlations to estimate the cost of turbines presented above are for a range power below $5 \mathrm{MW}$ (some of these correlations are only applicable for a range power below $2 \mathrm{MW}$ ). In this paper, correlations to estimate the cost of conventional hydraulic turbines for a much bigger value of power have been developed. Table 6 represents these correlations with ranges of power and head, the number of studied turbines and their $\mathrm{R}^{2}$. The methodology represented above and the obtained data from many manufactures of costs depending on power and head are used to develop these correlations. It is noticeable that $\mathrm{R}^{2}$ exceeds $74 \%$ in all cases.

\begin{tabular}{|c|c|c|c|c|}
\hline $\begin{array}{l}\text { Type of } \\
\text { turbine }\end{array}$ & $\begin{array}{l}\text { Number } \\
\text { of studied } \\
\text { turbines }\end{array}$ & $\begin{array}{l}\text { The power and the net } \\
\text { head ranges }\end{array}$ & Developed correlation & $\mathrm{R}^{2}$ \\
\hline Pelton & 13 & $\begin{array}{l}2 \mathrm{MW} \leq \mathrm{P} \leq 25 \mathrm{MW} \\
129 \mathrm{~m} \leq \mathrm{H} \leq 795 \mathrm{~m}\end{array}$ & $C_{\text {Pelton turbine }(M €)=1.984 P^{1.427}(M W) H^{-0.4808}(m)}$ & 0.8803 \\
\hline Kaplan & 10 & $\begin{array}{l}5 \mathrm{MW} \leq \mathrm{P} \leq 233 \mathrm{MW} \\
12 \mathrm{~m} \leq \mathrm{H} \leq 42 \mathrm{~m}\end{array}$ & 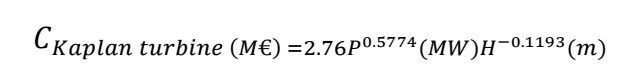 & 0.938 \\
\hline Francis & 24 & $\begin{array}{l}1 \mathrm{MW} \leq \mathrm{P} \leq 32 \mathrm{MW} \\
17 \mathrm{~m} \leq \mathrm{H} \leq 573 \mathrm{~m}\end{array}$ & $C_{\text {Francis turbine }(M €)}=2.927 P^{1.174}(M W) H^{-0.4933}(m)$ & 0.9261 \\
\hline $\begin{array}{l}\text { Francis } \\
\text { reversible }\end{array}$ & 12 & $\begin{array}{l}74 \mathrm{MW} \leq \mathrm{P} \leq 1000 \mathrm{MW} \\
72 \mathrm{~m} \leq \mathrm{H} \leq 630 \mathrm{~m}\end{array}$ & $C_{\text {Francis reversible }(M €)=13.39 P^{0.5825}(M W) H^{-0.3359}(\mathrm{~m})}$ & 0.7468 \\
\hline
\end{tabular}

Table 6 Developed correlations to estimate the costs of Hydraulic turbines

Pelton turbine: It can be seen that the correlation of Pelton turbine is less sensitive to the net head but it is much more sensitive to the mechanical power variation (Table 6).

Kaplan turbine: It can be seen that the correlation of Kaplan turbine is less sensitive to the net head but it is more sensitive to the mechanical power variation. In addition, the correlation of Kaplan is less sensitive to the net head and to the mechanical power variation than the correlation of Pelton (Table 6).

Francis turbine: It can be seen that the correlation of Francis turbine is less sensitive to the net head but it is much more sensitive to the mechanical power variation. In addition, the correlation of Francis is less sensitive to the mechanical power variation than the correlation of Pelton (Table 6).

Francis reversible: It can be seen that the correlation of Francis reversible turbine is less sensitive to the net head but it is more sensitive to the mechanical power variation. In addition, the correlation of Francis 
reversible is less sensitive to the net head and to the mechanical power variation than the correlations of Pelton and Francis (Table 6).

It can be noticed that the correlations of Francis and Pelton are more sensitive to the net head and to the mechanical power variations than the correlations of Kaplan and Francis reversible. The correlation of Kaplan is less sensitive to the net head variation than the other developed correlations (Table 6).

\subsection{Pump and Pump as Turbine (PAT)}

A range of 73 centrifugal pumps is used to develop two new correlations to estimate the cost of pump $(\mathrm{P} \leq 2 \mathrm{MW})$ and a new correlation to estimate the cost of PAT $(\mathrm{P} \leq 550 \mathrm{~kW})$. The power range and the net head range studied in this paper are respectively, $(160 \leq \mathrm{P} \leq 2000)$ and $(30 \leq \mathrm{H} \leq 150)$. The cost includes the cost of pump, generator, hydraulic drive unit, installation kit. The data used in this study is provided from pumps manufacturers located in Belgium (KSB).

In order to construct a more accurate estimate to evaluate the cost of pump, the used data have divided into two range, $[0 ; 1000 \mathrm{~kW}]$ and $[1000 \mathrm{~kW} ; 2000 \mathrm{~kW}]$ and consequently two correlations have been developed.

Table 7 represents the developed correlations to estimate the cost of pump (for $160 \mathrm{~kW} \leq \mathrm{P} \leq 1000 \mathrm{~kW}$ and $50 \mathrm{~m} \leq \mathrm{H} \leq 150 \mathrm{~m}$ ), the developed correlation to estimate the cost of pump (for $1000 \mathrm{~kW}<\mathrm{P} \leq 2060$ $\mathrm{kW}$ and $70 \mathrm{~m} \leq \mathrm{H} \leq 150 \mathrm{~m})$ and the developed correlation to estimate the cost of PAT $(\mathrm{P} \leq 550 \mathrm{~kW}$ and $25 \mathrm{~m} \leq \mathrm{H} \leq 200 \mathrm{~m}$ ), the number of studied turbines and their $\mathrm{R}^{2}$. It is noticeable that $\mathrm{R}^{2}$ exceeds $90 \%$ in all cases.

Table 7 Developed correlations to estimate the cost of pump and PAT

\begin{tabular}{|c|c|c|c|c|}
\hline & $\begin{array}{l}\text { Number of studied } \\
\text { turbines }\end{array}$ & $\begin{array}{l}\text { The power and the net } \\
\text { head ranges }\end{array}$ & Developed correlation & $\mathrm{R}^{2}$ \\
\hline \multirow{2}{*}{ Pump } & 31 & $\begin{array}{l}160 \mathrm{~kW} \leq \mathrm{P} \leq 1000 \mathrm{~kW} \\
50 \mathrm{~m} \leq \mathrm{H} \leq 150 \mathrm{~m}\end{array}$ & $C_{E M, P u m p}(€)=1753 P^{0.9623}(\mathrm{~kW}) H^{-0.3566}(\mathrm{~m})$ & 0.9637 \\
\hline & 42 & $\begin{array}{l}1000 \mathrm{~kW}<\mathrm{P} \leq 2060 \mathrm{~kW} \\
70 \mathrm{~m} \leq \mathrm{H} \leq 150 \mathrm{~m}\end{array}$ & $C_{E M, P u m p}(€)=1451 P^{1.69}(\mathrm{~kW}) H^{-0.4066}(\mathrm{~m})$ & 0.9928 \\
\hline PAT & 42 & $\begin{array}{l}\mathrm{P} \leq 550 \mathrm{~kW} \\
25 \mathrm{~m} \leq \mathrm{H} \leq 200 \mathrm{~m}\end{array}$ & $C_{E M, P u m p(€)}=1355.6 P^{0.8296}(\mathrm{~kW}) \mathrm{H}^{-0.1035}(\mathrm{~m})$ & 0.9228 \\
\hline
\end{tabular}

Pumps ( $\mathrm{P} \leq 1 \mathrm{MW})$ : It can be seen that the developed correlation of pump $(\mathrm{P} \leq 1 \mathrm{MW})$ is less sensitive to the net head but it is more sensitive to the mechanical power variation (Table 7).

Pumps ( $1 \mathrm{MW}<\mathrm{P} \leq 2 \mathrm{MW})$ : It can be seen that the developed correlation of pump (1MW $<\mathrm{P} \leq 2 \mathrm{MW})$ is less sensitive to the net head but it is more sensitive to the mechanical power variation. It can be noted that the correlation of pump ( $1 \mathrm{MW}<\mathrm{P} \leq 2 \mathrm{MW})$ is more sensitive to the net head and the mechanical power variation than the correlation of pump $(\mathrm{P} \leq 1 \mathrm{MW})$ (Table 7).

PAT $(\mathrm{P} \leq 550 \mathrm{~kW})$ : It can be seen that the developed correlation of PAT $(\mathrm{P} \leq 550 \mathrm{~kW})$ is not really sensitive to the net head but it is more sensitive to the mechanical power variation (Table 7).

It can be noticed that the correlations of pumps $(\mathrm{P} \leq 1 \mathrm{MW}$ and1000 $\mathrm{kW}<\mathrm{P} \leq 2060)$ and PAT are more sensitive to the mechanical power variations than the net head. The correlation of pumps for power range $(1000 \mathrm{~kW}<\mathrm{P} \leq 2060)$ is more sensitive to the variation of mechanical power than pumps for a powers range $(160 \mathrm{~kW} \leq \mathrm{P} \leq 1000 \mathrm{~kW})$ and $\mathrm{PAT}$. 


\section{RESULTS and DISCUSSIONS}

\subsection{Comparison Between Real and Simulated Costs}

Comparison between real and simulated costs of hydropower plants equipped with Pelton, Kaplan, Francis and Francis reversible turbines are represented in Tables 8-11, respectively.

The error is calculated by using the following equation:

$$
\text { Error }=\frac{\text { Market cost }- \text { Estimated cost }}{\text { Market cost }}
$$

\subsubsection{Hydraulic turbines}

Pelton turbines: The resulting correlation simulates with good agree with real cost of the power plants with an average error of $4 \%$ (Table 8 ) and with a quite good fit of $\mathrm{R}^{2}$ of $88.03 \%$ (Table 6). The range of incurred error is between $-19 \%$ and $25 \%$. The largest error appears for a power level of $13 \mathrm{MW}$ (Table 8).

Table 8 Comparison between real and simulated costs of hydro power plants equipped with Pelton turbine

\begin{tabular}{ccccc}
\hline $\mathrm{P}(\mathrm{MW})$ & $\mathrm{H}(\mathrm{m})$ & Market cost $(\mathrm{M} €)$ & Estimation $(\mathrm{M} €)$ & Error \\
\hline 2 & 129 & 0,48 & 0,52 & $-7 \%$ \\
3 & 297 & 0,66 & 0,62 & $7 \%$ \\
5 & 144 & 2,03 & 1,81 & $11 \%$ \\
6 & 142 & 2,16 & 2,36 & $-9 \%$ \\
7 & 240 & 2,26 & 2,29 & $-1 \%$ \\
8 & 255 & 2,26 & 2,69 & $-19 \%$ \\
9 & 354 & 2,4 & 2,72 & $-13 \%$ \\
13 & 293 & 6,72 & 5,03 & $25 \%$ \\
13 & 373 & 5,07 & 4,47 & $12 \%$ \\
17 & 502 & 6,5 & 5,69 & $12 \%$ \\
21 & 304 & 10,5 & 9,79 & $7 \%$ \\
25 & 795 & 9,8 & 7,91 & $19 \%$ \\
& & & Mean & $4 \%$ \\
\hline
\end{tabular}

Kaplan turbines: The resulting correlation simulates with good agree with real cost of the power plants with an average error of $0 \%$ (Table 9) and with a quite good fit of $\mathrm{R}^{2}$ of $93.8 \%$ (Table 6). The range of incurred error is between $-15 \%$ and $21 \%$. The largest error appears for a power level of $30 \mathrm{MW}$ (Table 9).

Table 9 Comparison between real and simulated cost of hydro power plants equipped with Kaplan turbine

\begin{tabular}{cccccc}
\hline Turbine & $\mathrm{P}(\mathrm{MW})$ & $\mathrm{H}(\mathrm{m})$ & Market cost $(\mathrm{M} €)$ & Estimated cost $(\mathrm{M} €)$ & Error \\
\hline 1 & 5 & 17 & 4,46 & 4,98 & $-12 \%$ \\
2 & 8 & 42 & 5,8 & 5,87 & $-1 \%$ \\
3 & 14 & 30 & 9,95 & 8,44 & $15 \%$ \\
4 & 30 & 17 & 17,66 & 14,02 & $21 \%$ \\
5 & 51 & 22 & 18,24 & 18,47 & $-1 \%$ \\
6 & 70 & 12 & 26,1 & 23,83 & $9 \%$ \\
7 & 125 & 27 & 28,22 & 30,23 & $-7 \%$ \\
8 & 125 & 23 & 30,23 & 30,82 & $-2 \%$ \\
9 & 128 & 20 & 30,84 & 31,77 & $-3 \%$ \\
10 & 233 & 35 & 36,36 & 41,99 & $-15 \%$ \\
& & & & Mean & $0 \%$ \\
\hline
\end{tabular}


Francis turbines: The resulting correlation simulates with good agree with real cost of the power plants with an average error of $-1 \%$ (Table 10) and with a quite good fit of $\mathrm{R}^{2}$ of $92.61 \%$ (Table 6). The range of incurred error is between $-28 \%$ and $28 \%$. The largest error appears for a power level of $3 \mathrm{MW}$ and 7 MW (Table 10).

Table 10 Comparison between real and simulated cost of hydro power plants equipped with Francis turbine

\begin{tabular}{ccccccc}
\hline Turbine & $\mathrm{P}(\mathrm{MW})$ & $\mathrm{H}(\mathrm{m})$ & $\mathrm{Q}(\mathrm{m} 3 / \mathrm{s})$ & Real cost $(\mathrm{M} €)$ & Estimated cost $(\mathrm{M} €)$ & \\
\hline 2 & 1 & 41 & 3 & 0,60 & 0,48 & $21 \%$ \\
3 & 2 & 81 & 3 & 0,97 & 0,77 & $21 \%$ \\
4 & 3 & 114 & 3 & 1,10 & 1,04 & $6 \%$ \\
5 & 3 & 80 & 4 & 0,97 & 1,24 & $-28 \%$ \\
6 & 4 & 93 & 5 & 1,66 & 1,62 & $3 \%$ \\
7 & 4 & 81 & 5 & 1,62 & 1,73 & $-7 \%$ \\
8 & 4 & 96 & 4 & 1,45 & 1,59 & $-10 \%$ \\
9 & 4 & 161 & 3 & 0,97 & 1,23 & $-27 \%$ \\
10 & 4 & 158 & 3 & 1,10 & 1,24 & $-13 \%$ \\
11 & 4 & 573 & 1 & 0,60 & 0,66 & $-9 \%$ \\
12 & 6 & 242 & 3 & 1,81 & 1,62 & $11 \%$ \\
13 & 6 & 77 & 9 & 3,46 & 2,86 & $17 \%$ \\
14 & 6 & 193 & 3 & 1,61 & 1,81 & $-13 \%$ \\
15 & 6 & 73 & 8 & 3,63 & 2,93 & $19 \%$ \\
16 & 7 & 145 & 6 & 3,46 & 2,50 & $28 \%$ \\
17 & 7 & 75 & 11 & 4,00 & 3,47 & $13 \%$ \\
18 & 8 & 58 & 15 & 5,45 & 4,60 & $16 \%$ \\
19 & 9 & 90 & 11 & 5,21 & 4,26 & $18 \%$ \\
20 & 10 & 106 & 10 & 4,84 & 4,44 & $8 \%$ \\
21 & 13 & 90 & 16 & 6,45 & 6,55 & $-2 \%$ \\
22 & 15 & 67 & 25 & 8,00 & 8,97 & $-12 \%$ \\
23 & 15 & 44 & 40 & 9,98 & 11,04 & $-11 \%$ \\
24 & 32 & 343 & 11 & 8,06 & 9,75 & $-21 \%$ \\
& & & & & Mean & $-1 \%$ \\
\hline
\end{tabular}

Francis reversible turbines: The resulting correlation simulates with good agree with real cost of the power plants with an average error of $-2 \%$ (Table 11 ) and with a quite good fit of $\mathrm{R}^{2}$ of $74.68 \%$ (Table 6). The range of incurred error is between $-19 \%$ and $25 \%$. The largest error appears for a power level of $380 \mathrm{MW}$ (Table 11).

Table 11 Comparison between real and simulated cost of hydro power plants equipped with Francis reversible turbine

\begin{tabular}{cccccc}
\hline Turbine & $\mathrm{P}(\mathrm{MW})$ & $\mathrm{H}(\mathrm{m})$ & Real cost (Million $€$ ) & Simulated cost (Million $€$ ) & Error (\%) \\
\hline 1 & 74 & 200 & 28,93 & 27,71 & $4 \%$ \\
2 & 108 & 554 & 24,2 & 24,53 & $-1 \%$ \\
3 & 120 & 143 & 44,35 & 41,11 & $7 \%$ \\
4 & 130 & 72 & 56,84 & 54,23 & $5 \%$ \\
5 & 157 & 315 & 34,68 & 36,87 & $-6 \%$ \\
6 & 185 & 520 & 36,28 & 34,28 & $5 \%$ \\
7 & 213 & 520 & 33,53 & 37,22 & $-11 \%$ \\
8 & 240 & 365 & 38,6 & 44,93 & $-16 \%$ \\
9 & 250 & 500 & 38,95 & 41,40 & $-6 \%$ \\
10 & 342 & 481 & 44,99 & 50,34 & $-12 \%$ \\
11 & 380 & 629 & 60,4 & 48,91 & $19 \%$ \\
12 & 1000 & 630 & 80,85 & 85,90 & $-6 \%$ \\
& & & & Mean & $-2 \%$ \\
\hline
\end{tabular}




\subsubsection{Pump and PAT}

Comparison between real and simulated costs of pumps and PAT are represented in Tables 12-14, respectively.

Pumps $(\mathrm{P} \leq 1 \mathrm{MW})$ : The resulting correlation simulates with good agree with real cost of the pump with an average error of $0 \%$ (Table 12) and with a quite good fit of $\mathrm{R}^{2}$ of $96.37 \%$ (Table 7). The range of incurred error is between $-18 \%$ and $16 \%$. The largest error appears for a power level of $438 \mathrm{~kW}$ (Table 12).

Table 12 Comparison between real and simulated cost of pump (Power $\leq 1 \mathrm{MW})$

\begin{tabular}{cccccc}
\hline Pump & $\mathrm{H}(\mathrm{m})$ & $\mathrm{P}(\mathrm{kW})$ & Real Cost $(€)$ & Simulated cost $(€)$ & Error \% \\
\hline 1 & 50 & 161,15 & $69.204,52$ & $57.802,54$ & $16 \%$ \\
2 & 70 & 220,28 & $71.211,57$ & $69.257,19$ & $3 \%$ \\
3 & 90 & 294,5 & $87.623,50$ & $83.733,61$ & $4 \%$ \\
4 & 50 & 311,01 & $102.343,38$ & $108.824,32$ & $-6 \%$ \\
5 & 110 & 360,87 & $87.630,02$ & $94.789,44$ & $-8 \%$ \\
6 & 130 & 426,96 & $97.041,82$ & $104.995,65$ & $-8 \%$ \\
7 & 70 & 438,15 & $113.771,79$ & $134.231,24$ & $-18 \%$ \\
8 & 50 & 478,94 & $143.112,73$ & $164.878,38$ & $-15 \%$ \\
9 & 150 & 509,05 & $119.157,83$ & $118.168,94$ & $1 \%$ \\
10 & 90 & 567,47 & $143.458,03$ & $157.404,92$ & $-10 \%$ \\
11 & 50 & 613,48 & $232.863,72$ & $209.232,69$ & $10 \%$ \\
12 & 70 & 664,16 & $200.416,18$ & $200.305,55$ & $0 \%$ \\
13 & 110 & 707,92 & $183.478,38$ & $181.284,66$ & $1 \%$ \\
14 & 50 & 766,44 & $259.024,28$ & $259.216,44$ & $0 \%$ \\
15 & 130 & 829,98 & $210.394,47$ & $199.052,89$ & $5 \%$ \\
16 & 90 & 860,27 & $221.315,41$ & $234.908,15$ & $-6 \%$ \\
17 & 70 & 871,66 & $288.606,65$ & $260.205,21$ & $10 \%$ \\
18 & 150 & 959,28 & $241.436,87$ & $217.427,17$ & $10 \%$ \\
19 & 110 & 1034,64 & $268.283,87$ & $261.187,86$ & $3 \%$ \\
& & & & Mean & $0 \%$ \\
\hline
\end{tabular}

Pumps (1MW $<\mathrm{P} \leq 2 \mathrm{MW})$ : The resulting correlation simulates with good agree with real cost of the pump with an average error of $0 \%$ (Table 13) and with a very good fit of $\mathrm{R}^{2}$ of $99.28 \%$ (Table 7). The range of incurred errors is between $-6 \%$ and $4 \%$. The largest error appears for a power level of 1709 $\mathrm{kW}$ (Table 13).

Table 13 Comparison between real and simulated cost of pump $(1 \mathrm{MW} \leq$ Power $\leq 2 \mathrm{MW})$

\begin{tabular}{lllllll}
\hline Pump & $\mathrm{Q}(\mathrm{m} 3 / \mathrm{h})$ & $\mathrm{H}(\mathrm{m})$ & $\mathrm{P}(\mathrm{kW})$ & Total Cost $(€)$ & Estimated cost $(€)$ & Error \\
\hline 1 & 3000 & 110 & 1034,64 & $268.283,87$ & $268.934,05$ & $0 \%$ \\
2 & 5000 & 70 & 1060,12 & $342.834,45$ & $336.764,19$ & $2 \%$ \\
3 & 4000 & 90 & 1105,32 & $344.764,23$ & $326.295,18$ & $5 \%$ \\
4 & 3000 & 130 & 1209,5 & $336.405,86$ & $327.208,50$ & $3 \%$ \\
5 & 4000 & 110 & 1315,62 & $399.475,40$ & $403.726,04$ & $-1 \%$ \\
6 & 5000 & 90 & 1379,03 & $456.150,14$ & $474.341,98$ & $-4 \%$ \\
7 & 3000 & 150 & 1394,23 & $382.408,61$ & $392.589,08$ & $-3 \%$ \\
8 & 4000 & 130 & 1638,32 & $548.934,64$ & $546.620,99$ & $0 \%$ \\
9 & 5000 & 110 & 1709,41 & $592.274,04$ & $628.608,34$ & $-6 \%$ \\
10 & 4000 & 150 & 1888,15 & $652.821,54$ & $655.611,28$ & $0 \%$ \\
11 & 5000 & 130 & 2062,08 & $843.397,82$ & $806.545,11$ & $4 \%$ \\
12 & 5000 & 150 & 2383,45 & $1.004 .079,82$ & $972.129,52$ & $3 \%$ \\
& & & & & Mean & $0 \%$ \\
\hline
\end{tabular}

PAT $(\mathrm{P} \leq 550 \mathrm{~kW})$ : The resulting correlation simulates with good agree with real cost of the PAT with an average error of $-2 \%$ (Table 14) and with a quite good fit of $\mathrm{R}^{2}$ of $92.28 \%$ (Table 14). The range of incurred error is between $-27 \%$ and $22 \%$. The largest error appears for a power level of $18 \mathrm{~kW}$. 
Table 14 Comparison between real and simulated cost of hydro power plants equipped with PAT

\begin{tabular}{|c|c|c|c|c|c|}
\hline Pump & Head (m) & Power $(\mathrm{kW})$ & Real cost of PAT $(€)$ & Simulated cost $(€)$ & Error $(\%)$ \\
\hline 1 & 72 & 6 & 4.874 & 3.785 & $22 \%$ \\
\hline 2 & 50 & 7,53 & 5.808 & 4.668 & $20 \%$ \\
\hline 3 & 25 & 9 & 5868 & 5.856 & $0 \%$ \\
\hline 4 & 50 & 10,54 & 6.265 & 6.174 & $1 \%$ \\
\hline 5 & 50 & 13,33 & 6.265 & 7.506 & $-20 \%$ \\
\hline 6 & 50 & 18 & 7587 & 9.635 & $-27 \%$ \\
\hline 7 & 100 & 25,70 & 10.078 & 11.979 & $-19 \%$ \\
\hline 8 & 100 & 31,52 & 12.511 & 14.196 & $-13 \%$ \\
\hline 9 & 100 & 41 & 16155 & 17.665 & $-9 \%$ \\
\hline 10 & 25 & 44 & 25856 & 21.914 & $15 \%$ \\
\hline 11 & 50 & 45 & 18289 & 20.644 & $-13 \%$ \\
\hline 12 & 150 & 50,82 & 16.155 & 20.172 & $-25 \%$ \\
\hline 13 & 25 & 72 & 31920 & 33.005 & $-3 \%$ \\
\hline 14 & 200 & 75 & 27958 & 26.989 & $3 \%$ \\
\hline 15 & 50 & 85 & 29798 & 35.033 & $-17 \%$ \\
\hline 16 & 25 & 90 & 37922 & 39.735 & $-5 \%$ \\
\hline 17 & 50 & 120 & 49617 & 46.669 & $6 \%$ \\
\hline 19 & 150 & 140 & 50345 & 46.853 & $7 \%$ \\
\hline 20 & 51 & 150,95 & 60.335 & 56.354 & $7 \%$ \\
\hline 21 & 50 & 161 & 69.204 & 59.590 & $14 \%$ \\
\hline 22 & 50 & 177,50 & 61.944 & 64.627 & $-4 \%$ \\
\hline 23 & 100 & 180 & 75652 & 60.453 & $20 \%$ \\
\hline 24 & 200 & 180 & 64391 & 55.895 & $13 \%$ \\
\hline 25 & 200 & 180,00 & 64391 & 55.895 & $13 \%$ \\
\hline 26 & 70 & 220,28 & 71.212 & 74.451 & $-5 \%$ \\
\hline 27 & 70 & 220,28 & 71.212 & 74.451 & $-5 \%$ \\
\hline 28 & 100 & 244,00 & 99.076 & 77.855 & $21 \%$ \\
\hline 29 & 90 & 294,50 & 87.624 & 92.129 & $-5 \%$ \\
\hline 30 & 100 & 299,00 & 112.267 & 92.193 & $18 \%$ \\
\hline 31 & 50 & 311,01 & 102.343 & 103.031 & $-1 \%$ \\
\hline 32 & 100 & 351,00 & 112.276 & 105.344 & $6 \%$ \\
\hline 33 & 110 & 360,87 & 87.630 & 106.646 & $-22 \%$ \\
\hline 34 & 130 & 426,96 & 97.042 & 120.358 & $-24 \%$ \\
\hline 35 & 70 & 438,15 & 113.772 & 131.894 & $-16 \%$ \\
\hline 36 & 150 & 465,00 & 152.671 & 127.136 & $17 \%$ \\
\hline 37 & 150 & 509,05 & 119.158 & 137.075 & $-15 \%$ \\
\hline \multirow[t]{2}{*}{38} & 150 & 547,00 & 161.597 & 145.521 & $10 \%$ \\
\hline & & & & Mean & $-2 \%$ \\
\hline
\end{tabular}

\subsection{Graphics Representation of the Developed Correlations to Estimate the Cost of for Different Values of Head}

\subsubsection{Hydraulic turbine}

Graphics representation of the developed correlations to estimate the cost of Pelton, Kaplan, Francis and Francis reversible turbines for different values of head are represented respectively in Figs. 6-9. It can be seen from these figures that the cost increases for high power levels but it decreases for high head. It can be explained by the fact that when the head decreases, the size of turbines increases and consequently the cost increases.

The highest cost sensitivity to the net head is registered for Francis turbine and the lowest cost sensitivity to the net head is registered for the cost of Kaplan. The cost sensitivity to the net head increases with the increase of the mechanical power. 


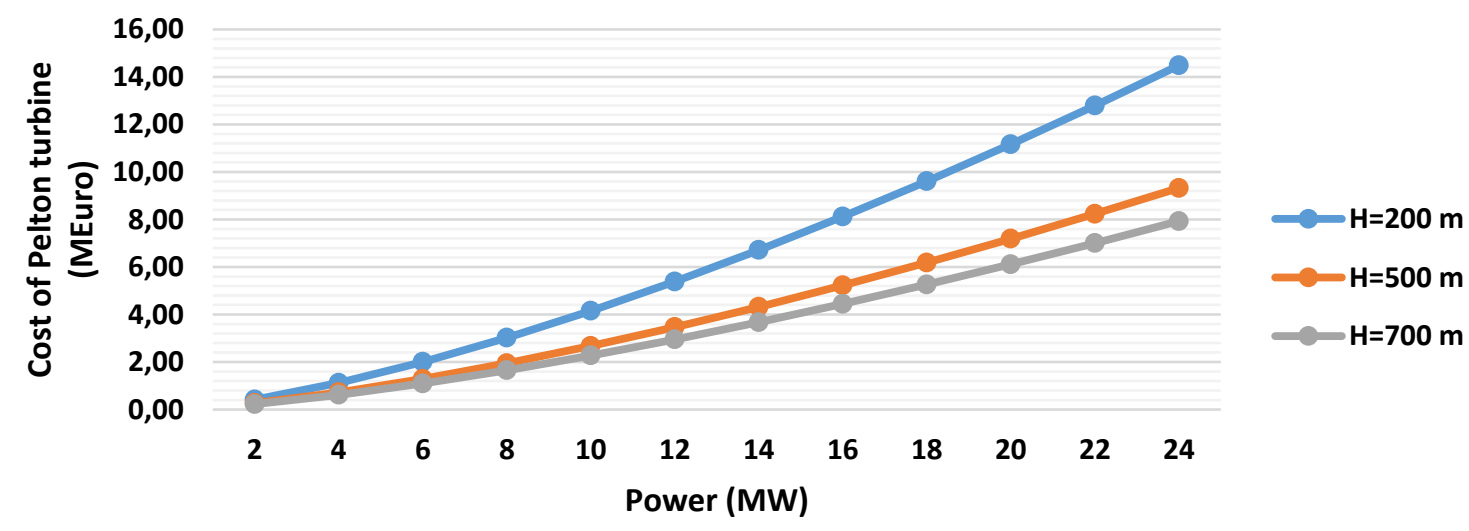

Figure 6 Graphic representation of the cost of Pelton turbine $(P \leq 25 \mathrm{MW})$ for different values of head

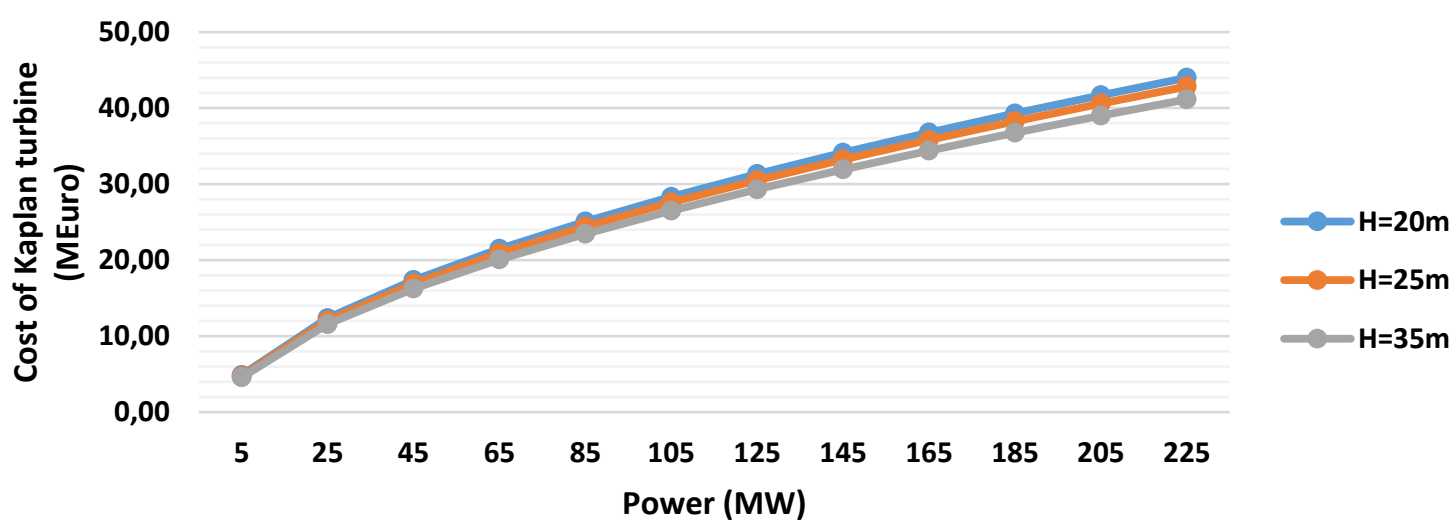

Figure 7 Graphic representation of the cost of Kaplan turbine $(P \leq 225 \mathrm{MW})$ for different values of head

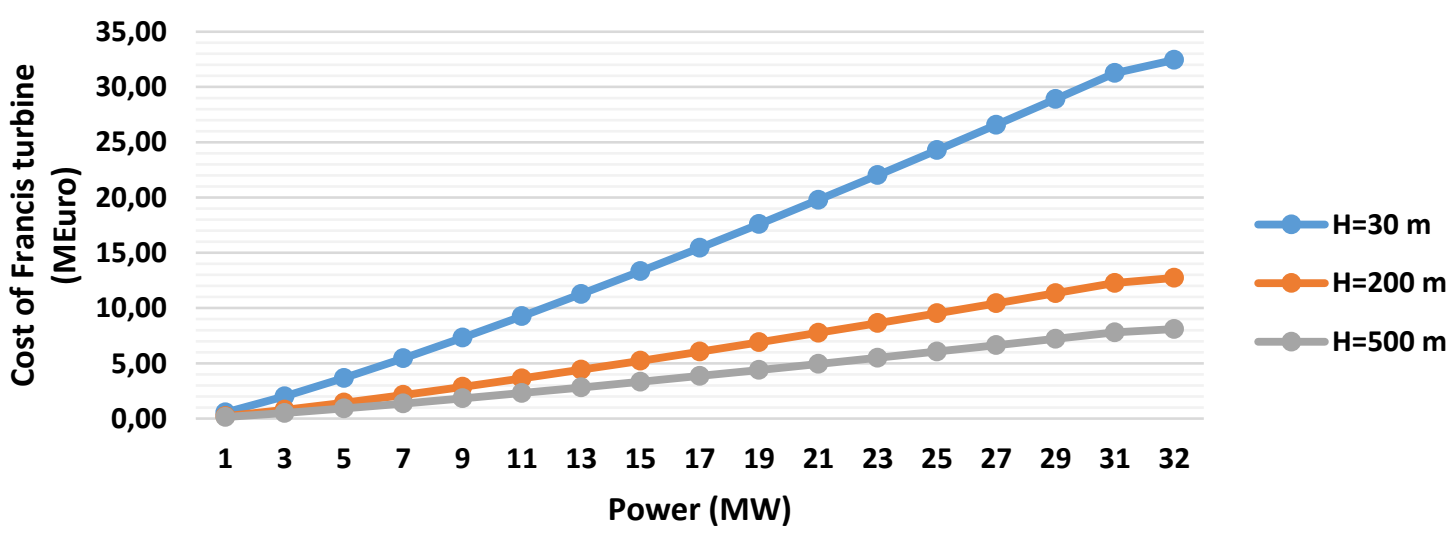

Figure 8 Graphic representation of the cost of Francis turbine $(P \leq 32 \mathrm{MW})$ for different values of head 


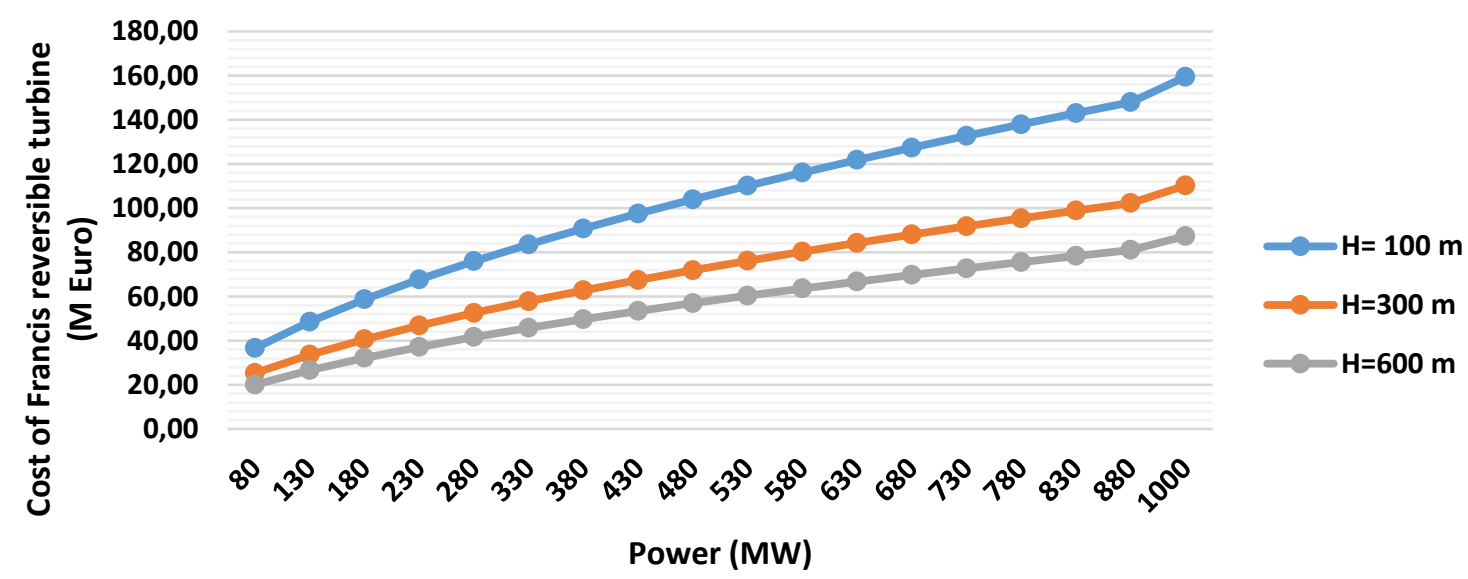

Figure 9 Graphic representation of the cost of Francis reversible turbine $(P \leq 1000 \mathrm{MW})$ for different values of head

\subsubsection{Pumps and PAT}

The cost function of a pump with a power $\leq 2 \mathrm{MW}$ and for PAT with a power $\mathrm{P} \leq 550 \mathrm{~kW}$ obtained from the developed correlations in this paper for different values of head are graphically shown in Figs. 10-12. It can be seen from these figures that the cost increases for high power levels but it decreases for high head. It can be explained by the fact that when the head decreases, the size of pump increases and consequently the cost increases.

The highest cost sensitivity to the net head is registered for pumps for a power range ( $1 \mathrm{MW}<\mathrm{P} \leq 2 \mathrm{MW})$ and the lowest cost sensitivity to the net head is registered for the cost of PAT.

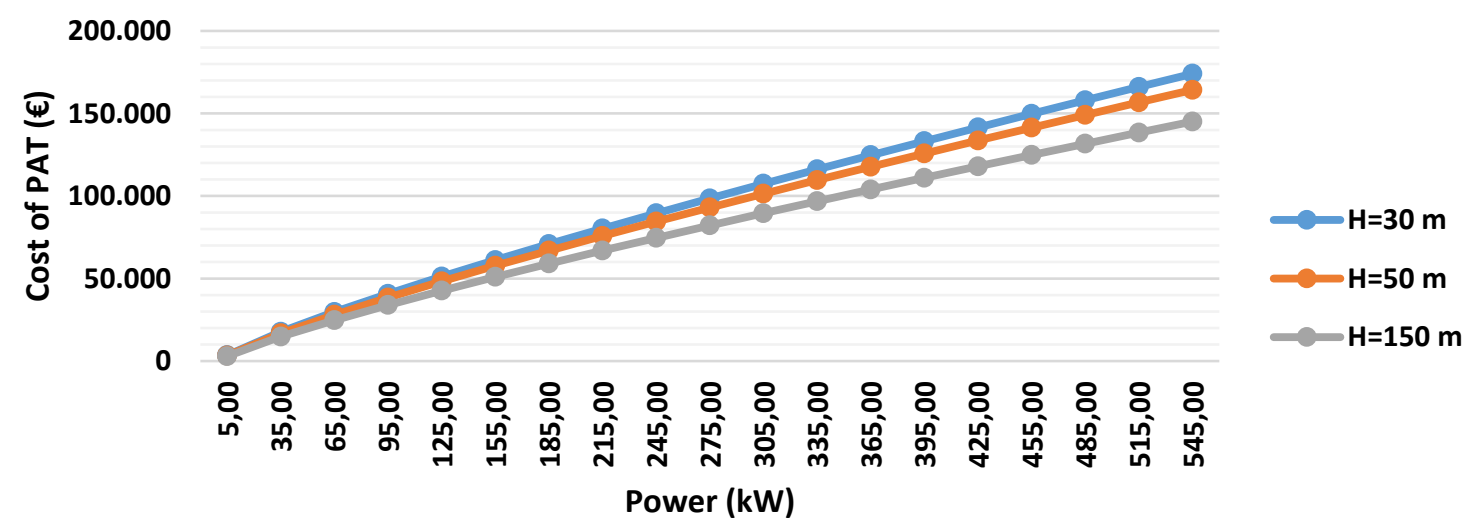

Figure 10 Graphic representation of the cost of PAT $(P \leq 550 \mathrm{~kW})$ for different values of head 


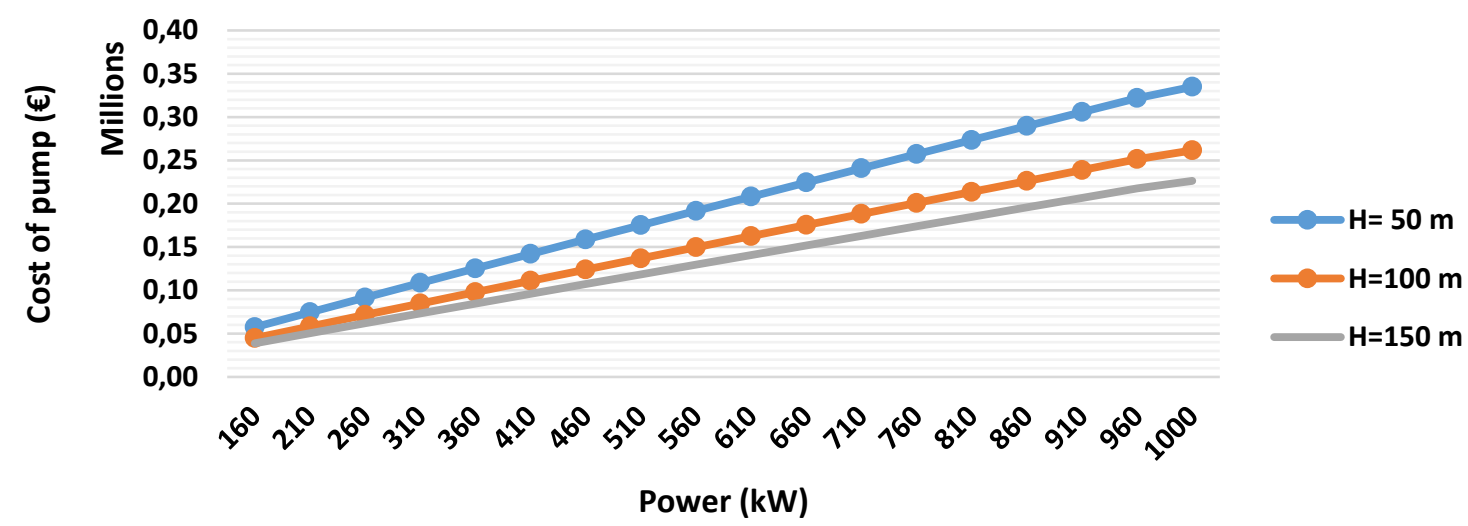

Figure 11 Graphic representation of the cost of pump $(P \leq 1000 \mathrm{~kW})$ for different values of head

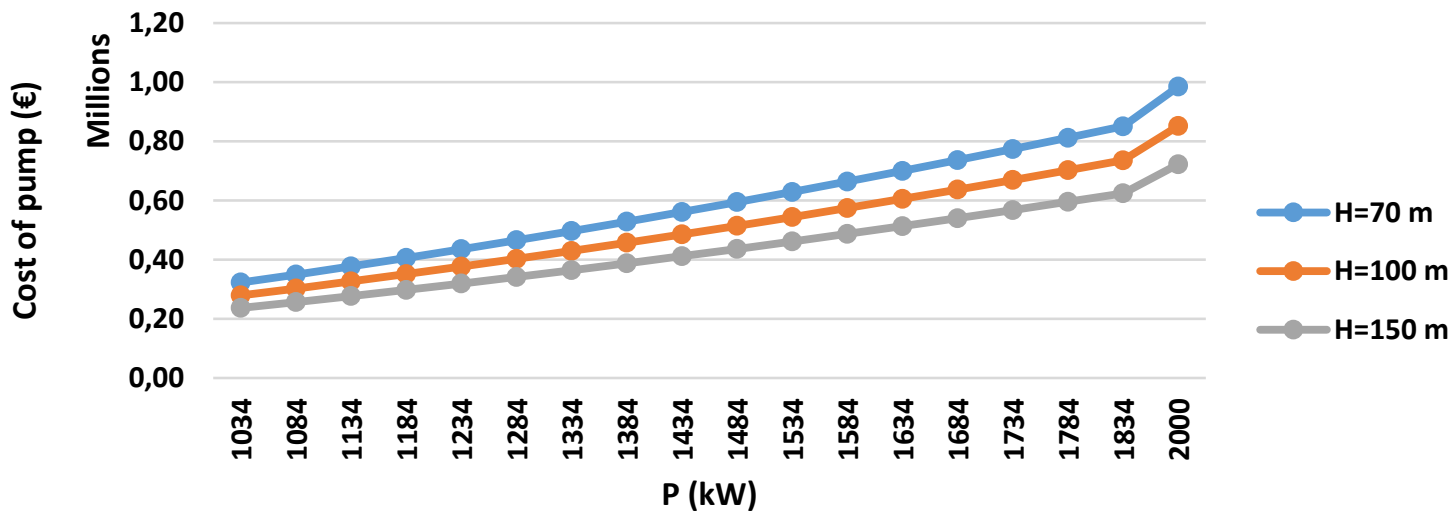

Figure 12 Graphic representation of the cost of pump (1004 $\mathrm{kW} \leq P \leq 2060 \mathrm{~kW})$ for different values of head

\section{CONCLUSIONS}

The following conclusions can be drawn from the results of the present study:

An overview of existing estimating techniques to estimate the cost of hydraulic turbines has been presented in this paper.

New correlations have been developed to estimate the cost of Pelton ( $\mathrm{P} \leq 25 \mathrm{MW})$, Kaplan (5 MW $\leq \mathrm{P}$ $\leq 233 \mathrm{MW})$, Francis $(1 \mathrm{MW} \leq \mathrm{P} \leq 32 \mathrm{MW})$ and Francis reversible turbines (74 MW $\leq \mathrm{P} \leq 1000 \mathrm{MW})$. The $\mathrm{R}^{2}$ exceeds $74 \%$ in all cases.

New correlations have been developed in this study to estimate the cost of pump ( $\mathrm{P} \leq 2 \mathrm{MW})$ and a new correlation to estimate the cost of PAT $(\mathrm{P} \leq 550 \mathrm{~kW})$. The $\mathrm{R}^{2}$ exceeds $90 \%$ in all cases.

The correlation of Francis and Pelton are more sensitive to the net head and the mechanical power variations than the correlations of Kaplan and Francis reversible. The correlation of Kaplan is less sensitive to the net head variation than the other developed correlations. The cost sensitivity to the net head increases with the increase of the mechanical power. 
The correlation of pump $(1 \mathrm{MW}<\mathrm{P} \leq 2 \mathrm{MW})$ is more sensitive to the net head and the mechanical power variation than the correlation of pump $(\mathrm{P} \leq 1 \mathrm{MW})$.

The cost of EM equipment increases with an increase of the power but it decreases with a decrease of the net head.

\section{REFERENCES}

[1] Hino, T. and A. Lejeune, Pumped storage hydropower developments. Comprehensive Renewable Energy, 2012. 6: p. 405-434.

[2] Jain, S.V. and R.N. Patel, Investigations on pump running in turbine mode: a review of the state-of-the-art. Renewable and Sustainable Energy Reviews, 2014. 30: p. 841-868.

[3] Sayann, K., Hydro turbines for SHP. International course on Small Hydropower development, Indian Institute of Technology, Roorkee February, 2004: p. 186-216.

[4] Ogayar, B. and P. Vidal, Cost determination of the electro-mechanical equipment of a small hydro-power plant. Renewable Energy, 2009. 34(1): p. 6-13.

[5] Zainuddin, H., et al., Design and development of pico-hydro generation system for energy storage using consuming water distributed to houses. World Academy of Science, Engineering and Technology, 2009. 59: p. $154-159$.

[6] Thoma, D. and C. Kittredge, Centrifugal pumps operated under abnormal conditions. Power, 1931. 73: p. 881884.

[7] Knapp, R., Centrifugal-Pump Performance as Affected by Design Features. Transactions of the ASME, 1941: p. 251-260.

[8] Fernandez, J., et al., Performance of a centrifugal pump running in inverse mode. Proceedings of the Institution of Mechanical Engineers, Part A: Journal of Power and Energy, 2004. 218(4): p. 265-271.

[9] Shafer, L. and A. Agostinelli, Using pumps as small turbines. International Water Power and Dam Construction, 1981. 33(11).

[10]Ramos, H. and A. Borga, Pumps yielding power. Dam Engineering, Water Power \& Dam Construction, 2000. 10(4): p. 197-217.

[11]Hanif, C.M., Applied hydraulic transients. 1987, Van Nostrand Reinhold Company New York.

[12]Isbăşoiu, E.C., et al. Using standard pumps as turbines. in proceeding to the CEEs conference. 2007.

[13]Fecarotta, O., A. Carravetta, and H. Ramos, CFD and comparisons for a pump as turbine: mesh reliability and performance concerns. Int J Energy Environ, 2011. 2(1): p. 39-48.

[14] Yang, S.-S., et al., Effects of blade wrap angle influencing a pump as turbine. Journal of Fluids Engineering, 2012. 134(6): p. 061102.

[15]Alatorre-Frenk, C., Cost minimisation in micro-hydro systems using pumps-as-turbines. 1994, University of Warwick.

[16]Motwani, K., M Tech thesis, Experimental and Numerical Investigations on Pump as Turbine for Micro Hydropower Plants. Mechanical Engineering Department, Institute of Technology, Nirma University, 2012.

[17]Chuenchooklin, S., Development of Pico-hydropower Plant for Farming Village in Upstream Watershed. Thailand, Prosperity and Poverty in a Globalised World-Challenges for Agricultural Research, Tropentag, 2006.

[18]Chapallaz, J.-M., P. Eichenberger, and G. Fischer, Manual on pumps used as turbines. 1992: Vieweg.

[19]Ross, R. and V. Lobanoff, Centrifugal Pumps Design and Applications. 1992, Butterworth-Heinemann, Woburn, MA.

[20]Gordon, J. and A. Penman, Quick estimating techniques for small hydro potential. J. of Power Dam Constr, 1979. 31: p. 46-55.

[21]Lasu, S. and T. Persson, Mini power station in Sweden. Internationale Fachtagung über Umbau und Erweitrung von Wasserkraftanlagen, 1979. 34.

[22]Gulliver, J.S. and A. Dotan, Cost estimates for hydropower at existing dams. Journal of energy engineering, 1984. 110(3): p. 204-214.

[23]Whittington, H., A. Wallace, and D. Henderson. An economic analysis of capital costs in micro-hydro. in Proc., Third International Conference on Small Hydro, International Water Power \& Dam Construction. 1988.

[24]Voros, N., C. Kiranoudis, and Z. Maroulis, Short-cut design of small hydroelectric plants. Renewable Energy, 2000. 19(4): p. 545-563. 
[25]Chenal, R., Évaluation du cout de construction d'une petite centrale hydro-electrique nouvelle et complete et du prix revient du kWh (P $\leq 1$ '000 KW). URL: www. mhylab. com/fr/pages/pdf/cout_PCH. pdf (Accessed 22 June 2009), 2000.

[26]Mitthias, H., E. Doujak, and P. Angerer. A contribution to ecological-economical aspects of hydro power plants,». in Proceedings of 4th International Conference on Hydropower «, Bergen. 2001.

[27]Papantonis, D., Small hydro power stations. Simeon, Athens, Greece, 2001.

[28]Kaldellis, J., D. Vlachou, and G. Korbakis, Techno-economic evaluation of small hydro power plants in Greece: a complete sensitivity analysis. Energy Policy, 2005. 33(15): p. 1969-1985.

[29]Aggidis, G.A., et al., The costs of small-scale hydro power production: Impact on the development of existing potential. Renewable Energy, 2010. 35(12): p. 2632-2638.

[30]Singal, S. and R. Saini, Analytical approach for development of correlations for cost of canal-based SHP schemes. Renewable Energy, 2008. 33(12): p. 2549-2558.

[31]Singal, S. and R. Saini, Cost analysis of low-head dam-toe small hydropower plants based on number of generating units. Energy for Sustainable development, 2008. 12(3): p. 55-60.

[32]Singal, S., R. Saini, and C. Raghuvanshi, Analysis for cost estimation of low head run-of-river small hydropower schemes. Energy for sustainable Development, 2010. 14(2): p. 117-126.

[33]Cavazzini, G., et al., Accurate estimation model for small and micro hydropower plants costs in hybrid energy systems modelling. Energy, 2016. 103: p. 746-757.

[34]Gordon, J., Determining “'Ballpark' costs for a proposed project. Hydro Review, 2003. 11(1): p. 37-41.

[35]Kaldellis, J., The contribution of small hydro power stations to the electricity generation in Greece: technical and economic considerations. Energy policy, 2007. 35(4): p. 2187-2196. 